\title{
PENINGKATAN KUALITAS HIDUP PENDERITA DM MELALUI GERAKAN DSME BERBASIS KOMUNITAS
}

\author{
Liliskarlina $^{1^{*}}$, A. Saputri Mulyana ${ }^{2}$ \\ 1. Prodi S1 Kesehatan Masyarakat, Fakultas Kesehatan, Universitas Patria Artha, Indonesia \\ 2. Prodi S1 Ilmu Keperawatan, Fakultas Kesehatan, Universitas Patria Artha, Indonesia \\ Patria Artha Journal of Nursing Science \\ 2021. Vol. 5(1), 41 - 48 \\ *E-mail: liliskarlinafkm09@gmail.com Issn: 25495674 \\ e-issn: $2549 \mathbf{7 5 4 5}$ \\ Reprints and permission: \\ http://ejournal.patria-artha.ac.id/index.php/jns
}

\begin{abstract}
Abstrak
Latar Belakang : Salah satu faktor penyebab terjadinya penyakit degeneratif seperti Diabetes Melitus (DM) berkaitan dengan gaya hidup yang kurang tepat, termasuk makan dan aktivitas fisik. Kebiasaan makan pada komunitas orang Makassar dapat memicu terjadinya DM. Tujuan: penelitian ini bertujuan mengetahui efektivitas gerakan DSME berbasis komunitas terhadap peningkatan kualitas hidup penderita DM. Metode Penelitian: desain penelitian eksperimental melalui metode quasi experiment, Pengumpulan data dilakukan menggunakan instrumen DQOL (Diabetes Quality of Life) untuk mengetahui kualitas hidup penderita DM sebelum dan setelah intervensi (program Diabetes Self Management Education berbasis komunitas). Hasil: Ada pengaruh antara DSME (Diabetes Self Management Education) berasis kompunitas terhadap kualitas hidup pasien DM ( $\mathrm{p}$ value $=0,000$ ). Implikasi penelitian: Penelitian ini sangat berperan penting dalam mengetahui kualitas hidup penderita DM. Rekomendasi: perlu pelaksanaan program DSME berbasis peka budaya pada setiap Puskesmas yang diintegrasikan pada program Prolanis.
\end{abstract}

Kata kunci: DSME; Kualitas Hidup; Penderita DM 


\section{Pendahuluan}

Diabetes Melitus (DM) merupakan kelompok penyakit metabolik dengan karakteristik terjadinya peningkatan kadar glukosa darah melebihi batas normal. Salah satu klasifikasi DM adalah DM tipe 2 Epidemiologi penyakit DM semakin menunjukkan peningkatan signifikan. Riset Kesehatan Dasar (Riskesdas) tahun 2018 melaporkan bahwa prevalensi DM berdasarkan konsensus PERKENI 2011 pada penduduk umur $\geq 15$ tahun mencapai 8,5\% ${ }^{1}$. Meningkat dibanding data Riskesdas tahun 2013, dengan angka 6,9\% ${ }^{2}$. Bahkan, DM menempati urutan ke-3 dari 10 penyakit penyebab kematian di Indonesia pada tahun 2017 (Depkes, 2018) ${ }^{3}$. Berdasarkan hasil Riskesdas tahun 2013, prevalensi DM yang didiagnosis dokter di Kota Makassar berada pada urutan tertinggi kedua. Data Survailans Penyakit Tidak Menular Bidang P2PL pada Dinas Kesehatan Provinsi Sulawesi Selatan pada tahun 2015, terdapat 21.018 kasus dengan kematian akibat DM berjumlah 811 orang (Dinkes Kota Makassar, 2016) ${ }^{4}$. Beberapa faktor dapat memicu terjadinya DM diantaranya faktor yang dapat dimodifikasi berupa ras dan etnik, umur, jenis kelamin, riwayat keluarga dengan DM, riwayat melahirkan bayi dengan berat badan > 4000 gram, dan adanya riwayat lahir dengan BBLR $(<2500$ gram) (Pusdatin Kemenkes, 2014) ${ }^{5}$.

Pada masyarakat lokal Kota Makassar, makanan bermakna "apa-apa nikanre". Artinya semua jenis makanan dapat dimakan, yang penting bergizi. Namun konsep makanan bergizi di sini adalah makanan dengan cita rasa yang gurih dan manis. Seperti kue cucur, makanan khas yang dianggap memiliki kandungan gula tinggi. Masyarakat lokal sering dipertemukan dengan makanan tersebut, baik pada acara pertemuan sosial maupun acara adat. Studi Prof. Dr. Supriadi Hamdat, MA. menemukan $53,33 \%$ orang Makassar yang terdiagnosa DM belum merubah pola makan sebelum dan setelah sakit. Bahkan aktivitas makan pada masyarakat dilakukan untuk mengenyangkan perut yang lapar. Makan nasi sebanyak-banyaknya, agar dapat beraktivitas dengan baik (Hamdat, 2014) ${ }^{6}$.

Penatalaksanaan DM seharusnya dilakukan melalui pengelolaan serta pengendalian secara komprehensif. Diantaranya berupa penerapan pola hidup sehat seperti edukasi, latihan jasmani, dan terapi nutrisi medis (TNM) bersamaan dengan intervensi farmakologis. Salah satu program edukasi pada penderita DM dikenal dengan program Diabetes Self Management Education (DSME), suatu proses berkelanjutan untuk memfasilitasi pengetahuan, keterampilan, dan kemampuan penderita DM dalam melakukan perawatan mandiri. Sebuah studi menunjukkan bahwa program DSME berbasis keluarga dapat memengaruhi kualitas hidup penderita DM (Rahayu, et al., 2014) ${ }^{7}$. Menurut PERKENI (2015) tujuan penatalaksanaan secara umum adalah meningkatkan kualitas hidup penderita Diabetes Mellitus ${ }^{8}$.

Penelitian ini bertujuan untuk mengetahui gambaran kualitas hidup (quality of life) penderita DM pada orang Makassar sebelum dan sesudah intervensi Gerakan DSME berbasis komunitas, dan pengaruh Gerakan DSME berbasis komunitas terhadap kualitas hidup (quality of life) penderita DM pada orang Makassar.

Berbeda dengan penelitian yang dilakukan sebelumnya yang berbasis keluarga, penelitian ini menerapkan gerakan DSME berbasis komunitas dengan berfokus pada komunitas orang Makassar di Kota Makassar. Dalam konteks masyarakat lokal, salah satu bentuk perilaku sakit pada suku Makassar adalah berobat ke dukun. Edukasi merupakan sebuah langkah penatalaksanaan khusus dan menjadi aspek pertama dalam pengelolaan DM tipe 2. Gerakan Diabetes Self Management Education (DSME) dilakukan dengan program edukasi melalui DSME berbasis komunitas. Diharapkan kualitas hidup penderita DM tipe 2 cenderung lebih baik tanpa adanya depresi akibat kestabilan kadar gula darah yang sulit tercapai. 


\section{Metode}

Desain penelitian yang digunakan adalah penelitian eksperimental dengan metode quasi experiment melalui rancangan penelitian one group pre-post test design. Intervensi diberikan melalui program DSME (Diabetes Self Management Education) berbasis komunitas. Variabel yang akan diobservasi adalah kualitas hidup pada penderita DM dengan menggunakan instrumen DQOL (Diabetes Quality of Life).

Hasil

\section{Distribusi Frekuensi Berdasarkan Usia}

Tabel 1 Distribusi Frekuensi Berdasarkan Usia Responden

\begin{tabular}{crr}
\hline $\begin{array}{c}\text { Umur } \\
\text { Responden }\end{array}$ & Frekuensi & Persentase \\
\hline $26-35$ & 0 & 0,0 \\
$36-45$ & 4 & 13,3 \\
$46-55$ & 13 & 43,3 \\
$56-65$ & 13 & 43,3 \\
$>65$ & 0 & 0,0 \\
Total & 30 & 100,0 \\
\hline Sumber : Data Primer, 2020 &
\end{tabular}

Pengelompokan usia ini disusun berdasarkan kriteria Depkes RI tahun 2009. Berdasarkan tabel 1 , sebagian besar responden berada pada kelompok usia Lansia Awal (46-55 tahun) dan Lansia Akhir (56-65 tahun), yakni masing-masing mencapai 13 orang $(43,4 \%)$. Selebihnya, terdapat 4 orang responden $(13,3 \%)$ pada kelompok usia masa dewasa akhir (36-45 tahun).

2. Distribusi Frekuensi Berdasarkan Jenis Kelamin

Tabel 2 Distribusi Frekuensi Berdasarkan Jenis Kelamin Responden

\begin{tabular}{lrr}
\hline Jenis Kelamin & Frekuensi & Persentase \\
\hline Laki-laki & 8 & 26,7 \\
Perempuan & 22 & 73,3 \\
Total & 30 & 100,0 \\
\hline
\end{tabular}

Sumber : Data Primer, 2020

Berdasarkan tabel 2, sebagian besar responden berjenis kelamin perempuan, yakni sebanyak 22 responden $(73,3 \%$ ) dan jenis kelamin laki-laki sebanyak 8 responden $(26,7 \%)$.
3. Distribusi Frekuensi Berdasarkan Hasil Pemeriksaan Gula Darah

Tabel 3 Distribusi Frekuensi Berdasarkan Hasil Pemeriksaan Gula Darah Responden

\begin{tabular}{lrr}
\hline Jenis Kelamin & Frekuensi & Persentase \\
\hline Meningkat & 4 & 13,3 \\
\hline Tetap & 0 & 0,0 \\
\hline Menurun & 26 & 86,7 \\
\hline Total & 30 & 100,0 \\
\hline
\end{tabular}

Sumber : Data Primer, 2020

Berdasarkan tabel 3, sebagian besar responden mengalami penurunan Gula Darah setelah intervensi DSME, yakni mencapai 26 responden $(86,7 \%)$. Dan terdapat 4 responden $(13,3 \%)$ yang mengalami peningkatan Glukosa Darah setelah intervensi DSME.

4. Kualitas Hidup Penderita DM Tabel 4 Kualitas Hidup Responden PreDSME

\begin{tabular}{lrr}
\hline Kategori & Frekuensi & Persentase \\
\hline Cukup & 23 & 76,7 \\
Baik & 7 & 23,3 \\
\hline Total & 30 & 100 \\
\hline Sumber : Data Primer, 2020 &
\end{tabular}

Berdasarkan tabel 4, sebelum pemberian intervensi DSME, sebagian besar responden memiliki kualitas hidup yang cukup baik yakni 23 orang $(76,7 \%)$ dan 7 responden dengan kualitas hidup yang baik $(23,3 \%)$.

Tabel 5 Kualitas Hidup Responden PostDSME

\begin{tabular}{lrr}
\hline Kategori & Frekuensi & Persentase \\
\hline Cukup & 1 & 3,3 \\
Baik & 29 & 96,7 \\
\hline Total & 30 & 100 \\
\hline
\end{tabular}

Sumber : Data Primer, 2020

Berdasarkan tabel 5 , setelah pemberian intervensi DSME, sebagian besar responden memiliki kualitas hidup yang baik yakni 29 orang $(96,7 \%)$ dan 1 responden dengan kualitas hidup yang cukup baik $(3,3 \%)$. 
5. Analisis Bivariat

Tabel 7 Pengaruh DSME terhadap Kualitas Hidup Pasien DM
Selain itu, studi ini juga menunjukkan bahwa sebelum pemberian intervensi DSME, sebagian besar responden memiliki

\begin{tabular}{|c|c|c|c|c|c|c|c|c|c|}
\hline & & \multicolumn{5}{|c|}{ Paired Differences } & \multirow[t]{3}{*}{$\mathrm{t}$} & \multirow[t]{3}{*}{ df } & \multirow[t]{3}{*}{ Sig. (2-tailed) } \\
\hline & & \multirow[t]{2}{*}{ Mean } & \multirow[t]{2}{*}{ Std. Deviation } & \multirow[t]{2}{*}{ Std. Error Mean } & \multicolumn{2}{|c|}{$\begin{array}{l}\text { 95\% Confidence Interval of the } \\
\text { Difference }\end{array}$} & & & \\
\hline & & & & & Lower & Upper & & & \\
\hline Pair 1 & Pre Test - Post Test & $-23,000$ & 10,570 & 1,930 & $-26,947$ & $-19,053$ & $-11,918$ & 29 &, 000 \\
\hline
\end{tabular}

Interpretasi : Nilai sig $=0,000<0,05$ artinya ada pengaruh antara DSME (Diabetes Self Management Education) berasis kompunitas terhadap kualitas hidup pasien DM.

\section{Pembahasan}

Studi ini menunjukkan bahwa sebagian besar responden berada pada kelompok usia Lansia Awal (46-55 tahun) dan Lansia Akhir (56-65 tahun), yakni masing-masing mencapai 13 orang $(43,4 \%)$. Selebihnya, hanya 4 responden $(13,3 \%)$ yang berada pada kelompok usia masa dewasa akhir (36-45 tahun).

Berdasarkan observasi di lapangan, memang sebagian besar pasien DM yang terlapor di Puskesmas Kanjilo, Kabupaten Gowa, adalah kelompok usia lansia. Namun, meskipun lansia, mereka memiliki semangat dan motivasi yang kuat dalam melakukan kunjungan dan pemeriksaan di Puskesmas tersebut. Hal ini semakin didukung dengan giat dan aktifnya tenaga kesehatan di Puskesmas dalam melakukan program kerja Prolanis. Terbukti, setiap pekan di hari Jumat pasien terlibat aktif mengikuti senam DM di halaman Puskesmas.

Hasil penelitian ini juga membuktikan bahwa sebagian besar responden mengalami penurunan Gula Darah setelah pemberian intervensi DSME, yakni mencapai 26 responden (86,7\%). Dan hanya 4 responden $(13,3 \%)$ yang mengalami peningkatan Gula Darah setelah intervensi DSME. Pemeriksaan Gula Darah ini dilakukan sebelum dan setelah intervensi DSME oleh tenaga kesehatan Puskesmas. kualitas hidup yang cukup baik yakni 23 orang $(76,7 \%)$ dan 7 responden dengan kualitas hidup yang baik $(23,3 \%)$. Namun, angka ini semakin membaik setelah pemberian intervensi DSME. Dimana frekuensi responden yang memiliki kualitas hidup yang baik meningkat, yakni 29 orang $(96,7 \%)$ dan hanya 1 responden dengan kualitas hidup yang cukup baik $(3,3 \%)$.

Berdasarkan hasil analisis bivariat, studi ini membuktikan adanya pengaruh antara DSME (Diabetes Self Management Education) berasis kompunitas terhadap kualitas hidup pasien DM ( $\mathrm{p}$ value = 0,000).

Diabetes Self-Management Education (DSME) adalah suatu proses berkelanjutan yang dilakukan untuk memfasilitasi pengetahuan, keterampilan, dan kemampuan pasien diabetes mellitus untuk melakukan perawatan mandiri. Hal ini dilakukan untuk dapat mengoptimalkan kontrol metabolik, dan mencegah komplikasi penderita Diabetes Mellitus. DSME dapat mendukung pengambilan keputusan, perawatan diri, pemecahan masalah, dan kolaborasi aktif dengan tim kesehatan untuk meningkatkan hasil klinis, status kesehatan, kualitas hidup penderita DM. Penelitian menunjukkan bahwa DSME dapat mencegah risiko terjadinya ulkus diabetik pada pasien DMT2 (Yuanita, et al., 2014).

Saat ini, jumlah orang yang menderita penyakit kronis semakin meningkat. Di Indonesia, persentase penyakit kronis, seperti diabetes, jauh lebih tinggi dibandingkan dengan penyakit menular dan kecelakaan. Menurut data International Diabetes Federation (2017), jumlah penderita diabetes meningkat dan 
tidak diragukan lagi jumlahnya akan terus meningkat di masa depan. Pendidikan kesehatan merupakan kegiatan yang penting dan selalu dibutuhkan oleh pasien untuk memahami bagaimana mereka akan mengelola penyakit mereka dan hidup sehat dengan itu.

Namun, pendidikan kesehatan itu sendiri tidak cukup untuk memotivasi pasien untuk tetap sehat dengan penyakit mereka apalagi jika pendidikan kesehatan diberikan tanpa persiapan dan tanpa memperhatikan tingkat literasi kesehatan dan budaya pasien. Gaya hidup yang kurang tepat dan kebiasaan diet yang kurang baik pada beberapa suku di Indonesia termasuk suku Bugis-Makassar merupakan pemicu terjadinya penyakit Diabetes Mellitus Tipe 2 (DMT2).

Pemberian edukasi kepada masyarakat yang menderita DMT2 dengan mengacu kepada Diabetes Self-Management Education (DSME) yang disesuaikan dengan budaya orang Bugis-Makassar terbukti efektif dapat membantu masyarakat untuk meningkatkan kualitas hidupnya.

Secara eksternal, budaya ikut memengaruhi lahirnya perbedaan persepsi tentang sehat-sakit dan bagaimana merespon kondisi tersebut, yang dalam ini disebut sebagai perilaku sehat-sakit pada kelompok masyarakat (Rew, 2014). Suku Bugis-Makassar merupakan satu diantara banyaknya suku bangsa yang ikut mewarnai corak kebudayaan di Indonesia. Corak perilaku dan dinamika orang BugisMakassar tersebut pun menjadi salah satu faktor yang ikut memengaruhi lahirnya konsep dan perilaku sehat-sakit yang berbeda. Sebuah studi menunjukkan bahwa sebagian orang Makassar menganggap dirinya sehat ketika dia dapat bergerak. Jadi, saat menemukan dirinya memiliki keterbatasan untuk bergerak, saat itulah menganggap dirinya dalam keadaan sakit (Hamdat, 2010).

Sebagian juga menganggap bahwa tubuh yang terlihat gemuk itulah yang disebut sehat. Orang-orang Makassar sering menyebutnya dengan istilah bajiki kalenna (tubuhnya baik karena gemuk) (Hamdat, 2010). Pemahaman ini yang membuat orang bugis-makassar memiliki pemahaman tersendiri mengenai pola makan dan jenis makanan yang dikonsumsi. Komunitas suku BugisMakassar, yang memiliki kecenderungan dalam memilih makanan yang manis dan gurih sebagai makanan bergizi Adanya ritualisasi dan kebiasaan makan yang secara berkesinambungan tersebut pada akhirnya memicu timbulnya penyakit diabetes melitus (DM) tipe 2. Apalagi DM tipe 2 merupakan penyakit degeneratif yang sangat erat kaitannya dengan pola hidup, termasuk diantaranya tentang pola makan (PERKENI, 2018).

Pendidikan kesehatan melalui program Diabetes Self-Management Education (DSME) ini telah dipersiapkan dengan baik dalam metode yang terstruktur untuk memberikan dampak yang lebih kepada responden. Sebab pendidikan kesehatan tidak akan efektif jika penyampaiannya tidak sesuai, petugas kesehatan tidak mempersiapkannya dengan baik, dan tidak memperhatikan latar belakang budaya pasien atau masyarakat setempat (Wong-\& Riege, 2013).

Hasil studi ini sejalan dengan beberapa penelitian sebelumnya. Beberapa studi menunjukkan manfaat penerapan DSME antara lain penerapan DSME pada discharge planning terbukti dapat meningkatkan self-efficacy pasien DMT2 secara signifikan dibandingkan dengan pemberian discharge planning biasa (Rondhianto, 2010). Selain itu, penerapan DSME pada pasien DM Tipe 2 juga dapat mengontrol kadar gula darah pasien DMT2 dan meningkatkan perawatan diri pasien sehingga bisa meningkatkan kualitas hidup pasien (Rahayu, Kamaluddin, \& Sumarwati, 2014).

\section{Simpulan}

Ada pengaruh antara DSME (Diabetes Self Management Education) berasis kompunitas terhadap kualitas hidup pasien DM ( $p$ value $=0,000)$. 


\section{Ucapan Terima Kasih}

Ucapan terimakasih kepada Kementerian Pendidikan dan Kebudayaan atas bantuan materi melalui dana hibah Simlitabmas pada program Penelitian Dosen Pemula, sehingga penelitian ini dapat terlaksana secara maksimal.

\section{Daftar Pustaka}

Al Fady \& Faisol, M. (2015). Madu dan luka diabetik, metodologi perawatan luka komplementer-dilengkapi dengan hasil riset. Yogyakarta: Gosyen Publishing.

Damayanti, S. 2015. Diabetes mellitus dan penatalaksanaan keperawatan. Yogyakarta: Nuha Medika.

Departemen Kesehatan RI. 2018. Data dan Informasi Profil Kesehatan Indoesia Tahun 2018. Diperoleh dari: http://www.depkes.go.id. Diakses pada tanggal 29 Maret 2019.

Dinas Kesehatan Kota Makassar. 2016. Profil kesehatan kota Makassar tahun 2015. Pemerintah Kota Makassar.

Hamdat, S. 2014. Budaya pangan dan gaya hidup keluarga makassar: dalam perspektif antropologis. Makassar: ASPublishing.

Hariyono \& Sababa, O., N. 2015. Diabetes Self Management Education Against Type 2 DM Patients Independence in Managing Diet. Jurnal INJEC. 2 (1). 48-51.

Isworo, A. \& Ekowati, W. 2014. The Effect of Tapping Therapy on Blood Glucose Levels in Type 2 Diabetes Mellitus Patients at Purwokerto. Jurnal INJEC. 1 (1). 93-96.

Nurkamilah, et al. 2018. Pengarus Diabetes Self Management Education (DSME/S) terhadap Diabetes Distress pada Pasien Diabetes Melitus Tipe 2 di RSD dr. Soebandi Jember. Pustaka Kesehatan. 6 (1). 133-140.
Perkumpulan Endokrinologi Indonesia (PERKENI). (2018). Pedoman pengelolaan dan pencegahan Diabetes Melitus tipe 2 dewasa di Indonesia. Jakarta: PB Perkeni

Powers, et al. 2015. Diabetes Self Management Educatio and Support in Type 2 Diabetes. The Diabetes Educator, $X X(X)$. Diperoleh dari: www.diabetes educator.org. Diakses pada tanggal: 29 Agustus 2018.

Purnama, W., T. \& Isnaeni, Y. 2018. Pengaruh Diabetes Self Management Education and Support (DSME/S) terhadap Stres pada Penderita Diabetes Mellitus Tipe 2 di Wilayah Kerja Puskesmas Gamping 1 Sleman Yogyakarta. Skripsi. Universitas

Aisyiyah: Yogyakarta.Pusat Data dan Informasi (Pusdatin) Kemenkes RI. 2014. Info Data dan Informasi Kesehatan. Diperoleh dari: www.depkes.go.id. Diakses pada tanggal 7 Maret 2019.

Rahayu, Kamaluddin, \& Sumarwati. (2014). Pengaruh DSME berbasis keluarga terhadap kualitas hidup penderita DM Tipe II di Wilayah Puskesmas II Baturaden. Journal Keperawatan Soedirman.9(3), 163-172.

Rew, L. (2014). The influence of culture on nursing practice and research. Journal for Specialists in Pediatric Nursing.19, 1-2. http:// doi.org/10.1111/jspn.12058

Riskesdas. 2018. Riset Kesehatan Dasar. Diperoleh dari: http://www.depkes.go.id. Diakses pada tanggal 29 Maret 2019.

Riskesdas. 2013. Riset Kesehatan Dasar. Diperoleh dari: http://www.depkes.go.id. Diakses pada tanggal 29 April 2019.

Rondhianto. (2010). Keterkaitan DSME terhadap self efficacy pasien diabetes mellitus. Jurnal Keperawatan. (3), 2, 216-229. ISSN: 2086-3071 
Wahid, R., A.,N. 2016. Pengaruh pendidikan kesehatan DSME terhadap kadar gula darah pasien Diabetes Tipe II di Prolanis Puskesmas Gajahan Surakarta (skripsi). Diperoleh dari: digilib.stikeskusumahusada.ac.id.

Diakses tanggal: 29 Agustus 2018.

Wiastuti, et. al. 2017. Pengaruh Diabetes Self Management Education and Support (DSME/S) Terhadap Stres pada Pasien Diabetes Melitus (DM) Tipe 2 Di Wilayah Kerja Puskesmas Patrang Kabupaten Jember. Pustaka Kesehatan. 5 (2). 260-275.

Wong-Rieger D, Rieger FP. (2013). Health Coaching in Diabetes: Empowering Patients to Self-Manage. Canadian Journal of Diabetes. 37(1):414

Yuanita, et al. 2014. Pengaruh DSME terhadap risiko terjadinya ulkus diabetik pada pasien rawat jalan dengan Diabetes Mellitus (DM) Tipe 2 di RSD dr. Soebandi Jember. Pustaka Kesehatan. 2 (1). Diperoleh dari: www.researchgate.net. Diakses pada tanggal 29 Agustus 2018. 
Patria Artha Journal of Nursing Science. Vol. 5, No.1, April 2021 